\title{
Energy Usage Attitudes of Urban India
}

\author{
Mohit Jain \\ IBM Research India \\ mohitjain@in.ibm.com
}

\author{
Deepika Chabra \\ IIIT Delhi, India \\ deepika1264@iiitd.ac.in
}

\author{
Jennifer Mankoff \\ HCII, CMU, USA \\ jmankoff@cs.cmu.edu
}

\author{
Amarjeet Singh \\ IIIT Delhi, India \\ amarjeet@iiitd.ac.in
}

\begin{abstract}
Though rapid increase in energy consumption has become a global problem, most of the solutions developed to address it for residential consumers are based on qualitative studies conducted with small numbers of users, typically in the developed world. Recent work has begun to explore consumption practices, and motivations, barriers and other factors affecting energy consumption in urban India. However, the small numbers of participants in those studies limit their generality. Our work contributes to this picture through a survey of 1724 residents of urban India, exploring the motivations and barriers affecting energy conservation and their opinions about sharing energy consumption data and future technologies for conservation. We found that urban Indians practice conservation because it is a learned habit and to save money, while comfort and convenience are the major barriers in conserving energy. Contrary to previous findings, we did not find a major influence of tradition, spirituality or moral reasons for conservation. Moreover, participants have minimal privacy concerns regarding sharing energy data. Interestingly, participants were not only interested in energy monitoring solutions, but were also positive about automated energy controlling systems, which contrasts previous findings. We conclude with design opportunities for this demographic such as information-sharing opportunities, appliance level consumption disaggregation, and convenient manual controls.
\end{abstract}

Index Terms-Energy, Sustainability, Survey, India.

\section{INTRODUCTION}

Global consumption of energy has increased steadily over the past decades. One solution, towards reducing the overall consumption, is to motivate people to decrease energy waste. Designing appropriate motivational technologies require an understanding of current consumption practices, attitude in terms of motivation, barriers towards conservation, and willingness to invest in understanding and conserving energy, besides other factors affecting energy use.

India is the world's second most populous country [1], and has economic growth of more than 7\% per year since 1997 [1]. These two trends have led to a substantial increase in national consumption of energy [2]. India became the fifth largest energy consumer in the world in 2006, emitting $4.4 \%$ of global carbon emissions [3]. Energy production has not been able to satisfy demands, resulting in approximately 400 million Indians with no access to electricity in 2010 [4]. According to International Energy Agency, the buildings sector accounts for the largest share (47\%) of India's energy use in 2005, with residential buildings accounting for a major $93 \%$ of the total building energy use [5]. In residential buildings, urban India constitutes a major share of Indian energy consumption (about $39 \%$ of energy use [6]), and a majority of urban households (91\%) have access to electricity [7]. In 2012, urban population was $32 \%$ of the total population [8]. Thus, an understanding of consumption and conservation practices in urban Indian households is crucial for designing appropriate technologies for this population.

There have been several qualitative studies [9]-[16] in residential and commercial settings, in both the developing and the developed world, which provide insight into these factors. However, all these studies were conducted with a limited numbers of participants (usually 10-40). In addition, only a few were conducted in urban Indian settings. Shrinivasan et al. [10] found that urban Indians have a culture of 'deep conservation', i.e., conservation practices are contextually imposed, habitual (to the point of being natural and unnoticed), deeply integrated into daily activities and involving a combination of traditional practices, manual effort, and technology. Vyas et al. [13] found similar results among middle class Indian household women, focusing on reuse practices. Sustainability practices were not necessarily driven by environmental goals, but were learned habits due to scarcity of resources. However such studies are ethnographic, qualitative in nature, and usually conducted with a small sample (11 participants [10], 10 participants [13], 17 participants [16]).

Some quantitative studies have been conducted in India as well, but they are either limited to establishing correlation between energy requirements and demographic variables [17], or explore deeply one of the factors related to conservation such as adoption of CFLs [18] or thermal comfort [12]. In this paper, we report on a large-scale paper-based door-to-door survey with 1724 participants from urban India (in and near Delhi). Our study sheds light on motivations, barriers, information sharing, and future technological solutions affecting energy consumption and conservation behavior. This is a replication study [19], and expands on the work done by Shrinivasan et al. [10] in a different city and at a much larger scale. By replicating at an increased scale, we may not only confirm or disprove prior findings, but more importantly, obtain statistically significant conclusions and gain deeper insights into factors affecting sustainability including the relative weights of different motivations and barriers. The primary data that we collected (accessible at: https://www.iiitd.edu.in/ amarjeet/UrbanIndiaSurvey/Data.zip) is one of the contributions of our paper. Similar to Shrinivasan et al. [10], we chose to focus on middle and high-income 
households in urban India because they have access to energy, and consume resources in more diverse ways (e.g., own multiple types of appliances) than other populations.

Our findings help to verify that urban Indians practice deep conservation (as previously defined by Shrinivasan et al. [10]). We find that money and learned habits early in life were the major motivators, while comfort and convenience were the major barriers, in conserving resources. We compare our results with previous work in the developing and developed world, and find similarities and differences. Contrary to previous findings [10], [13], we do not find that tradition, spirituality and moral motivations are a major influence in conservation behavior. Moreover, urban Indians have minimal privacy concerns, and are early adopters of cutting edge efficiency technologies when pricing is reasonable. Interestingly, participants are not only interested in energy monitoring solutions, but are also positive about automated energy control systems, which contradicts previous findings among Indian participants [10]. We conclude with design recommendations for urban Indian energy conservation technologies, including information-sharing opportunities, appliance level consumption disaggregation, and convenient manual controls.

\section{FACTORS AFFECTING CONSERVATION}

Many research studies have been conducted to explore energy conservation behaviors and attitudes in developed countries, particularly in the U.S., among different demographics including low-income households [11], typical middle-income households [9], [14], and green households [15]. Some of the themes highlighted in this body of work include reasons for saving energy (such as future generations, spirituality, ethics, habit, and trends), approaches to saving energy (such as repair work, re-use, efficient purchases and monitoring), and barriers to saving energy (such as money, safety, other household members and infrastructure inefficiencies). Other studies of routine domestic energy consumption practices in U.S. households and their interactions with specific devices [14] find that energy consumption interactions become unconscious, habitual and in some cases, irrational.

Focusing specifically on India, Pachauri et al. established a correlation between Indian household energy requirements and various socioeconomic characteristics from survey data for the year 1993-94 [17]. They found that income level was the most important factor influencing energy use, followed by literacy level, household size, and age of the head of the household. Pachauri et al. used secondary data from a survey conducted by the National Sample Survey, funded by the Government of India, which did not have data on conservation practices, motivations and barriers affecting conservation, sharing of consumption information, or about future conservation technologies. Qualitative studies in India have looked more deeply at the underlying factors driving energy use in residential households. Shrinivasan et al. [10] studied middle and high-income urban Indian residential consumers, and found 'deep conservation' practices which are deeply integrated into daily activities and contextually imposed. Other studies found that Indian middle-class women reuse and recycle worn-out household objects to enrich their everyday activities, and that factors such as religious belief, traditions, family intimacy, and personal hygiene, influence these sustainability practices [13].

Looking even more deeply at specific conservation practices, Indraganti et al. [12] studied thermal comfort among 45 apartment dwellers (113 participants) in Hyderabad, India. Using survey and interview data, they found that thermal comfort is achieved using natural ventilation, clothing, and other adaptive behaviors such as 'moving to an airy place' and 'drinking cold water'. Kumar et al. [18] explored the adoption of more efficient appliances and light bulbs (CFLs) in a survey of 900 participants from Delhi. They found that people lacks knowledge of CFLs, and proposed EDPOSTADIN (EDucation, POlicy support, STAndards, Demonstrations and INdustry involvement) to popularize CFLs.

Large-scale survey data about the range of behaviors and factors affecting conservation would complement these studies and help to answer questions about the prevalence of the specific qualitative results. As replication in HCI field has been gaining importance [19], we aimed to replicate the qualitative studies [9]-[11], [15] in quantitative manner to gain new insights into reasons affecting sustainability.

\section{STUDY DESIGN}

The aim of our study was to understand participants' appliance ownership, their current practices, motivations behind those practices, challenges faced in energy management, and future technology solutions.

\section{A. Method}

Our target population (urban middle-income Indian households) may not necessarily be on the Internet. Thus, we conducted a paper-based survey. We recruited thirty-six computer science undergraduate students ( 28 male, 8 female, all in the age group of 17-19 years) as interviewers to conduct the survey. All the interviewers were given course work credit for the mandatory community work that they do as part of their undergraduate degree requirement.

The survey was conducted from mid-June to July 2013, in NCR India (National Capital Region, which encompasses the entire city of Delhi as well as urban areas surrounding it in neighboring states of Haryana, Uttar Pradesh and Rajasthan). Interviewers used snowball sampling to recruit survey participants. Approximately 33\% of the people approached for the interview refused to participate, citing reasons such as lack of time and unwillingness to share information.

Interviewers read out the survey questions, and noted participant responses on paper forms. The surveys were later digitized on Survey Monkey by the interviewers for analysis purposes. Since all the survey questions were quantitative, the interviews were conducted in the local language of Hindi, though interviewers translated the responses reported on the web into English. An interview on an average took 40.19 minutes $(\mathrm{sd}=4.64)$. At the end of the survey, participants were 
given a booklet, prepared by the researchers, containing tips for conserving energy at home.

To ensure that each interviewer interpreted the survey questions in a similar manner, multiple training sessions were conducted with all of the interviewers. During these sessions, the interviewers were first asked to conduct one survey amongst themselves. Next, for each question in the survey, they were asked about their interpretation. Wherever there were gaps in the interpretation, we added a description in a script document that was provided to each interviewer for reference. After an initial five days of pilot surveys with real participants, another session was scheduled to discuss questions that may have arisen about the interviews. The survey script was updated accordingly.

\section{B. Procedure}

The survey collected information pertaining to characteristics of different home appliances (e.g., year of purchase, energy rating and scope for reduction); electricity consumption (e.g., who pays the bill, approximate bill for the previous cycle); motivations and barriers affecting different energy conservation practices; sharing of consumption information (e.g., with whom sharing occurs and how frequently); technologies that aid in reducing consumption (e.g., by providing detailed feedback or allowing control of appliances remotely); and demographics. Many of these questions were based on previous studies [9]-[11], [13]-[16], [20].

For collecting quantitative data about conservation practices, and motivations and barriers affecting conservation, we selected the ten most common conservation practices of urban residential Indians (from [10]). The participants were asked how frequently they perform those practices, and the motivation or barriers affecting their actions. We added a list of nine motivations and eight barriers (from [9]-[11], [13], [15]) for the interviewers to select from, though the participants were not made aware of this listing. If a participant mentioned a motivation/barrier that was not part of the list, the interviewers would briefly record it. All of the other survey questions were objective in nature with multiple options to choose from.

\section{Participants}

One thousand seven hundred twenty four participants $(56.2 \%$ male, $43.8 \%$ female, mean age $=37.7(\mathrm{sd}=14.1)$, median age $=38$ ) completed the survey, out of 1820 participants. Ninety-six participants started the survey but did not finish it, and hence were not considered for evaluation. The education level of the participants was distributed with $3.2 \%$ having only primary school education, $24.7 \%$ having high school education, $42.7 \%$ having college degrees, and $29.4 \%$ having post-graduate degrees. The majority $(51.6 \%)$ were working full-time, $25.9 \%$ were not working (among which $83 \%$ were home makers), and $22.0 \%$ were students. Most of the participants were married $(71.2 \%), 27.6 \%$ were single, and the rest were widowed, divorced or did not answer. An average participant household included 3.3 adults $(\mathrm{sd}=1.3)$ and 1.1 children $(\mathrm{sd}=0.9)$. A majority of the participants were living in an apartment $(65.6 \%)$, or a stand-alone house $(32.4 \%)$; on average, a house had 2.6 bedrooms $(\mathrm{sd}=1.1)$ and 1.93 bathrooms $(\mathrm{sd}=1.0)$. The household income was evenly distributed with $1.9 \%$ households earning below $1 \mathrm{~L}^{1}$ per year, 9.7\% 1-3 L, 22.2\% 3$5 \mathrm{~L}$ per year, 34.2\% 5-10 L per year, 21.6\% 10-20 L per year, $7.1 \%$ 20-50 L per year, $1.5 \%$ above $50 \mathrm{~L}$ per year, and $1.8 \%$ unknown. Most participants (72.2\%) paid their electricity bills themselves, while parents, relatives, or house owners paid the bills for the remainder $(26.1 \%)$. In the case of some rentals, the electricity bill was part of the fixed house rent, as there were no separate energy meters.

The surveyed population is representative of the urban population of Delhi. According to 2012 Delhi census data [21], $97.63 \%$ of Delhi population is urban. Among the urban Delhi population, $67.9 \%$ own their house, while $28.5 \%$ live in a rented house or apartment. On an average, a Delhi urban household has 1.74 bedrooms and 3.81 household members [21]. These values are close to our demographics. In total, the participants were from 117 different zip codes, with participation varying from 10 to 130 from a particular zip code. The survey was paper-based and participants were not chosen from the Internet.

\section{RESULTS}

All conservation practices in the survey were selected from previous work [10], which defines them as deep conservation, i.e., practices which are deeply integrated into daily activities and contextually imposed. Most of the participants $(\mathrm{m}=70.4 \%$, $\mathrm{sd}=10.9 \%$ ) regularly practiced all energy conservation practices mentioned in the survey. This confirms previous findings that urban Indians practice deep conservation. Moreover, on a 5point Likert scale, participants rated themselves high $(\mathrm{m}=3.8$, $\mathrm{sd}=1.1$ ) when asked about their orientation towards conservation, "I am environment- friendly and do everything possible to save the environment?" In this section, we present our results and compare findings of our work with previous related work in developing and developed world. Table I provides a summary of the comparison.

\section{A. Motivations}

Previous sustainability-related research in developed and developing countries have tried to identify reasons behind conservation of energy. This can help to guide the design of future technological solutions which can play on those motivations [22]. In studies undertaken in the U.S., common motivations found include protecting the environment for future generations [9], [11], [15], habit [11], [14], [15], saving money [9], [11], being environment-friendly [9], [15], and religious/ethics reasons [11], [15]. Studies with Indian participants [10], [13] identified similar motivations, including habit, money, religious/traditional/spiritual reasons, and to protect the environment. Moreover, Indians also conserve energy for health reasons [10], [13], and out of necessity [10] due to the scarcity of resources.

\footnotetext{
1 Annual Income is in units of Lakhs (L). One Lakh (L) is 100,000 INR, or
} approx. $\$ 2,000$. 
TABLE I. A COMPARISON OF KEY FINDINGS FROM OUR WORK AND PREVIOUS STUDIES CONDUCTED IN INDIA AND U.S.

\begin{tabular}{|c|c|c|}
\hline Result & $\begin{array}{l}\text { Findings from other U.S. based studies (Green [15], Typical [9], Low Income [11]), } \\
\text { and India based studies (Typical [10], Women [13]) }\end{array}$ & Our findings \\
\hline $\begin{array}{l}\text { Reasons for } \\
\text { Conservation }\end{array}$ & $\begin{array}{l}\text { US Typical: Money, Comfort, Convenience, Environment; What can I do? } \\
\text { US Green: Future generations; Activism; Religion/ethics, Trendy utopian optimism; } \\
\text { Rugged independence; Self-reliance; Habit } \\
\text { US Low Income: Future generations; Religion/ethics; Habit; Money; What can I do? } \\
\text { India Typical: Necessity; Practicality; Childhood Habit; Tradition; Comfort; Moral } \\
\text { values; Spirituality; Healthy living; Resource shortages; Money; Environment } \\
\text { India Women: Traditions; Religion beliefs; Family intimacy; Personal interests; Health }\end{array}$ & $\begin{array}{l}\text { Top Motivators: Money; } \\
\text { Habit; Environment } \\
\text { Least Motivators: Future } \\
\text { generations; Follow trends; } \\
\text { Ethics/Moral; } \\
\text { Cultural/Tradition/Spirituality }\end{array}$ \\
\hline $\begin{array}{l}\text { Barriers for } \\
\text { Conservation }\end{array}$ & $\begin{array}{l}\text { US Typical: Money; Poor technological interfaces; Inferior quality; Sharing } \\
\text { infrastructure or decisions with others; Safety } \\
\text { US Green: Quality of public transportation; Availability of products } \\
\text { US Low Income: Living space inefficiencies; Availability of services and products; } \\
\text { Habit; Sharing infrastructure or decisions with others; Safety; Money (esp. up-front } \\
\text { costs) } \\
\text { India Typical: Money, Safety, Comfort, Availability of resources }\end{array}$ & $\begin{array}{l}\text { Top Barriers: Comfort; 'do } \\
\text { not feel the need to do so' } \\
\text { Least Barriers: Safety; } \\
\text { Other people, including } \\
\text { household member; Lack of } \\
\text { information; Money }\end{array}$ \\
\hline $\begin{array}{l}\text { Consumption } \\
\text { Monitoring }\end{array}$ & $\begin{array}{l}\text { US Typical: Would like real-time information to help save money, have comfortable } \\
\text { homes, and be environmentally friendly. } \\
\text { US Green: Detailed tracking among "green" participants } \\
\text { US Low Income: Data and tools not available to participants } \\
\text { India Typical: Considered wasteful by some. Monitoring that could reduce pumping of } \\
\text { water used in one case }\end{array}$ & $\begin{array}{l}\text { Interested in monitoring } \\
\text { devices and appliance } \\
\text { controlling solutions }\end{array}$ \\
\hline
\end{tabular}

However with qualitative data, it is very hard to quantify the importance of different motivations for conservation. Hence we asked participants to describe the specific motivation behind each of the conservative actions they performed. For each participant, we calculated the number of times a motivation was mentioned, across the ten conservation practices. Motivations' count varied greatly. We found that 'saving money' was the most commonly cited motivation $(\mathrm{m}=3.1, \mathrm{sd}=2.0)$, followed by 'learned it at an early age, so it is habitual now' $(\mathrm{m}=1.5$, $\mathrm{sd}=1.6)$, and 'being environmentfriendly' $(\mathrm{m}=0.8, \mathrm{sd}=1.3)$. On the other hand, factors like 'providing a better life for future generations' $(\mathrm{m}=0.17$, $\mathrm{sd}=0.6)$, 'follow trends', $(\mathrm{m}=0.16$, $\mathrm{sd}=0.5)$, 'ethical or moral reasons' $(\mathrm{m}=0.14, \mathrm{sd}=0.6)$, 'cultural, traditional or spiritual reasons' $(\mathrm{m}=0.02, \mathrm{sd}=0.2)$, etc. mentioned in previous literature [9]-[11], [15], were not commonly reported. To find if the differences between motivations were significant, we conducted a one-way ANOVA (Analysis of Variance) on type of motivation (9), and found a significant main effect: Wilk's Lambda $=0.155, \quad \mathrm{~F}_{8,1712}=1232.3, \quad \mathrm{p}<0.001$. Pairwise comparisons showed that the means for all motivations were significantly different from each other, with the exception of 'providing a better life for future generations', 'following trends', and 'ethical or moral reasons'.

\section{B. Barriers}

Similar to motivations, it is crucial to understand the barriers restricting reductions in consumer energy consumption. U.S.-based studies with low-income [11] and typical residential household [9] found barriers such as money (up-front cost), sharing of infrastructure and/or decisions with others, lack of technology, and safety (e.g., keeping lights on to increase safety). Low-income households [11] have structural inefficiencies in their living spaces like air leaks, which was not mentioned by typical U.S. households [9]. Green U.S. participants did not mention any of the barriers listed above, and were concerned instead about public infrastructure and non-availability of environmentally friendly products [15]. Indian participants [10] have some similar barriers as U.S. typical and low-income participants, including money and safety. In addition, Indians also mentioned comfort and time as barriers restricting conservative actions.

In our study, we asked participants about specific barriers behind each of the conservative actions they were not able to perform to the extent they wanted to. Similar to motivation, we calculated number of times each barrier was mentioned. From the list of eight barriers, the topmost cited barrier was 'comfort and convenience' $(\mathrm{m}=1.3, \mathrm{sd}=1.4)$, followed by 'do not feel the need to do so' $(\mathrm{m}=1.0, \mathrm{sd}=1.2)$. On the other hand, barriers 
such as 'safety' $(\mathrm{m}=0.35, \mathrm{sd}=0.6)$, 'other people, including household member' $(\mathrm{m}=0.32$, $\mathrm{sd}=0.7)$, 'lack of information' $(\mathrm{m}=0.1, \mathrm{sd}=0.5)$ and 'money' $(\mathrm{m}=0.2, \mathrm{sd}=0.6)$ were amongst the bottom. To find if the differences between barriers were significant, we conducted a one-way ANOVA (Analysis of Variance) on the type of barrier (8), and found a significant main effect: Wilk's Lambda $=0.439, \mathrm{~F}_{8,1570}=330.6, \mathrm{p}<0.001$. Pairwise comparisons showed that the means for all barriers were significantly different from each other, with the exception of 'safety' and 'other people, including household members'.

\section{Sharing Consumption Data}

Previous research [22], [23] has shown that social comparison can act as a strong motivator to reduce energy use, but that requires sharing of consumption data (with or without anonymity) among users of the same community. U.S. study with green participants [15] found that the participants share information related to being green, in an activist manner. One of the participants' homes has thousands of visitors to learn about the green features in their home. Most of the green participants were very open to sharing consumption information, and also teaching conservative actions to other people in the community. Similarly, low-income U.S. participants [11] were found to share energy saving tips with their relatives, and also compare their electricity bills with each other. In contrast, typical U.S. residential participants [9] were less open to social comparison. For example, U.S. residential participants [9] preferred anonymous data, and were not inclined to share data directly due to privacy concerns. Indians, in general, are considered to have low privacy concerns compared to Americans [16], [24].

We measured privacy concerns using two questions. Firstly, we asked about participants' current habit of discussing energy bills and sharing energy saving practices with friends and neighbors. Secondly, we asked how comfortable participants are in sharing their energy bills and appliances usage details with specific groups including friends, families and neighbors. We found that $33.2 \%$ of the participants were currently sharing their bills, 36\% were discussing their energy conservation practices, and only $25.5 \%$ knew about their friends' or family's bills. However, regarding future energy use data sharing, a majority of the participants were completely fine with sharing energy bills with families $(86.05 \%)$, friends $(57.1 \%)$ and neighbors $(46.65 \%)$, though very few participants were in favor of sharing it on social network $(20.1 \%)$, or making the data public $(14.5 \%)$. Similar results were obtained for sharing data related to appliances owned and appliance use. Hence technologies that leverage sharing to motivate energy conservation may work well in Indian settings. This further builds upon the prior research that shows social comparison has the highest effect of conservation related behavior change [25].

\section{Consumption Monitoring Technologies}

Within the HCI community, a number of papers have been published on interaction designs for eco-visualization and feedback (e.g., [22], [26]). Such visualization and feedback technologies require monitoring energy consumption of the household. Some of the U.S. green participants [15] were already using real time monitoring and consumption tracking devices to aid in energy reduction, while other participants were positive about investing in detailed energy tracking devices for self-comparison purposes [22]. In comparison, U.S. low-income [11] and typical household [9] were interested in real-time energy consumption information to reduce their energy bills, however lacked the motivation and/or money to buy such monitoring tools. Some urban Indian participants [10] considered such monitoring technologies as potentially wasteful, as participants were well aware of their energy consumption, and hence were more interested in buying more energy efficient appliances, than monitoring systems.

We asked participants about changes they would like to have in their current energy bills, and about future technological solutions. A majority of the participants asked for more detailed information in their energy bill, with the top three (on a 5-point Likert scale ratings) being appliance-level consumption $(\mathrm{m}=4.3, \mathrm{sd}=0.8)$, strategies to reduce consumption $(\mathrm{m}=4.2, \mathrm{sd}=0.8)$, and comparison of the current month's total consumption with the past few months $(\mathrm{m}=4.1, \mathrm{sd}=0.8)$. Other information like showing 'ON' vs 'stand-by' status $(\mathrm{m}=3.3)$, comparison with neighborhood consumption levels $(\mathrm{m}=3.5)$, and daily and weekly consumption patterns $(\mathrm{m}=3.7)$, were rated low. Providing appliance-level consumption and appliance status information, and recommending customized strategies, requires data from energy monitoring devices.

In terms of future technological solutions, our participants rated these three highest: 'switch off appliances automatically when not in use' $(\mathrm{m}=4.3, \mathrm{sd}=0.8)$, 'automatically change appliance settings to save energy' $(\mathrm{m}=4.1, \mathrm{sd}=0.9)$, and 'enable collection of appliance-level data' $(\mathrm{m}=4.1, \mathrm{sd}=0.8)$. This is in contrast to previous results obtained for urban Indian households [10]. In spite of being aware of their energy bills, we found that our participants were not only interested in knowing more detailed energy consumption related information (including appliance level consumption), but were also positively inclined towards energy control systems. Checking and controlling status of appliances from outside the house seemed very convenient to our participants. Also, this solves the topmost barrier to conservation among our participants - 'comfort and convenience'. Moreover a majority of the participants agreed that they would be willing to invest Rs 1000 ( 20\$) (40.66\% participants) and Rs 1001-5000 (34.05\% participants) to buy such energy-saving technologies. This suggests that while our participants are open to new technology interventions, they are very cost conscious and hence the new smart home technologies need to be priced appropriately for them to have mass appeal.

\section{E. Appliance Ownership}

Our urban Indian participants displayed very high penetration of appliances, such as TV (99.3\% owned one or more TV, not including the 64 participants who chose not to respond), desktop/laptop (91.4\%, 168 no response), washing machine $(93.6 \%, 155$ no response), refrigerator $(99.3 \%, 75$ no response), water heater $(86.5 \%, 273$ no response), and air conditioner (85.5\%, 253 no response). Previous work has studied appliance ownership, specifically fans, TV and 

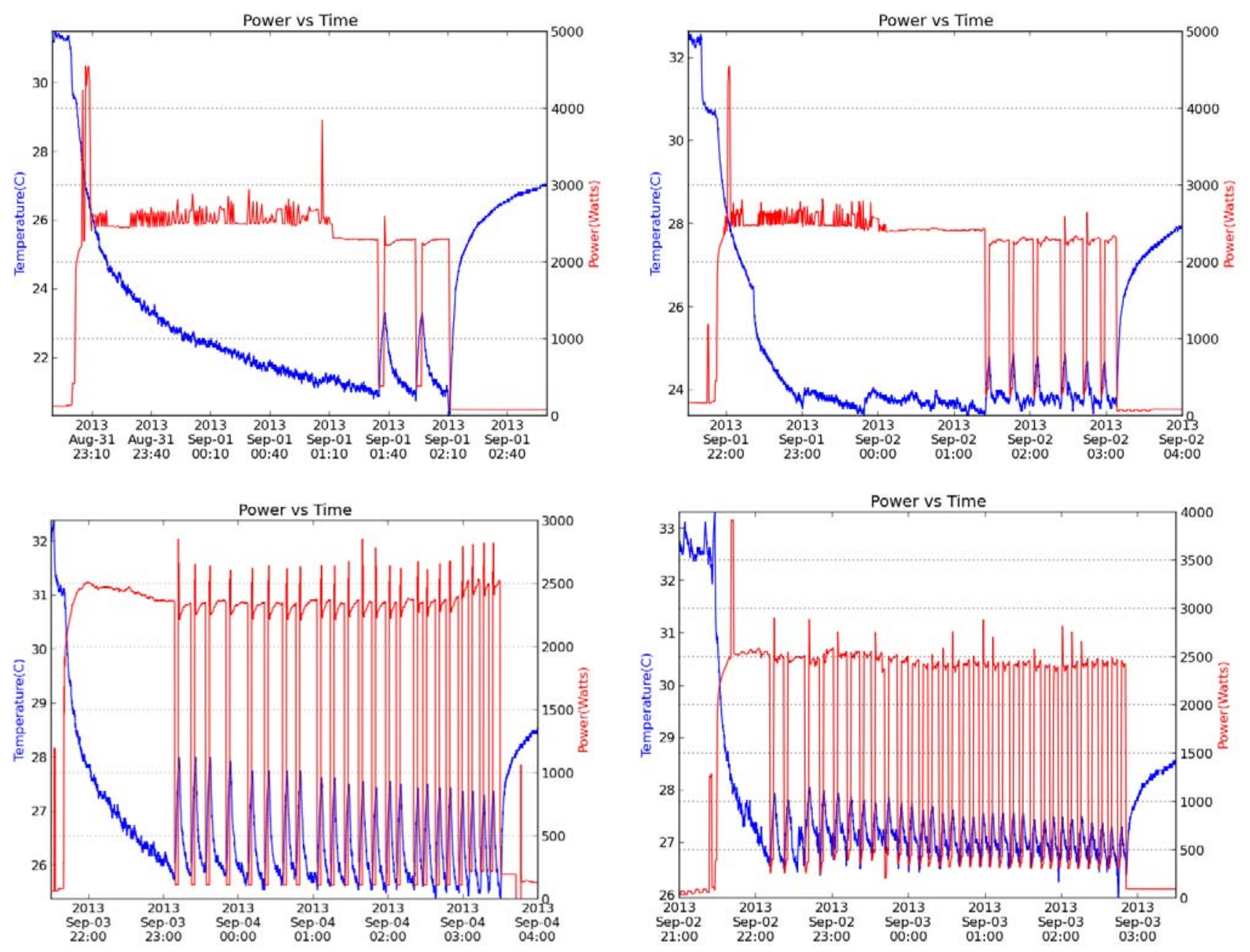

Fig. 1. Temperature and power consumption, set point: $21^{\circ} \mathrm{C}$ (top-left), $24^{\circ} \mathrm{C}$ (top-right), $26^{\circ} \mathrm{C}$ (bottom-left), $27{ }^{\circ} \mathrm{C}$ (bottom-right). Blue curve indicates temperature, while red curve represents power consumption as monitored from home level meter. Larger number of compressor cycles at higher temperature results in fluctuations in power consumption and hence reduction in total energy consumption.

refrigerator, using data collected by National Sample Survey Organization (NSSO) of India [27], and found similar results for urban population in area surrounding Delhi, i.e., TV $(\sim 81 \%)$ and refrigerator $(\sim 97 \%)$.

Moreover, we found a strong correlation between income level of the participants and the number of appliances they own, with Spearman's $r(1018)=0.601, p<0.001$. Similarly, a high correlation was obtained between monthly electricity bill and the number of appliances a participant owned, with Spearman's $r(974)=0.6, \mathrm{p}<0.001$.

\section{F. Holistic Sustainability}

Green participants in the U.S. were found to be actively concerned about conserving different resources, including energy, water and fuel [15]. Similarly, urban Indian participants showed conservation practices related to energy, water and fuel [10]. Such observations lead to the belief that environmental-friendly people are concerned about holistic conservation, and are not limited to energy. In our study, we found a strong correlation between participants who were aware of per unit electricity pricing and per unit water pricing, with Spearman's $r(1661)=0.513, \mathrm{p}<0.001$.

\section{G. Information (does not) lead to Conservation}

Previous studies [22] have shown that providing consumption information can help in reduction by supporting self-comparison, i.e., comparing one's current behavior with past behavior. However, we found contradicting results with no correlation between participants who pay their electricity bill themselves and participants who know the correct per unit of electricity cost, with Spearman's $r(1717)=0.071, \mathrm{p}<0.01$. We conducted a student's t-test to find that there is no significant difference in conservation practices among people who pay their electricity bill themselves and those who do not, with $t(1722)=1.76, p=0.079$ (mean difference $=0.053$, std. error difference $=0.03$; each conservation practice was rated based on how frequently the participant performed those practices, on a scale of 1-5). In contrast, using a student's t-test we found that there is a significant difference in conservation practices among people who correctly know per unit cost of electricity 
and those who do not, with $t(1713)=4.6, \mathrm{p}<0.001$ (mean difference $=0.13$, std. error difference $=0.29$ ). Thus it is hard to establish relationship between information (monthly billing and per unit energy pricing in our case) and conservative actions.

\section{H. Manual Controls}

Previous studies [10] have shown that participants are willing to mix manual and automated activities to achieve savings. Our survey found that a minority of the participants $(18.3 \%)$ kept their home air-conditioner (AC) in the automatic mode (Note: $12.4 \%$ participants did not have AC at home, and $14.7 \%$ participants chose not to answer). The remainder $(54.6 \%$ participants) used manual setting with minimum and maximum temperature set at $21.6{ }^{\circ} \mathrm{C}(\mathrm{sd}=6.96)$ and $24.6{ }^{\circ} \mathrm{C}(\mathrm{sd}=2.57)$, respectively. This is in range of the specified temperature by National building code of India: summer $\left(23-26^{\circ} \mathrm{C}\right)$ and winter $\left(21-23^{\circ} \mathrm{C}\right)$ [28].

To understand the relationship between AC temperature and energy consumption, we collected energy consumption data for different Air Conditioners at different temperature settings. Figure 1 presents data from one such air conditioner at different temperature settings (with similar external conditions). Comparison of energy consumption across different temperature settings clearly indicates significant energy savings at higher temperature settings $(\sim 50 \%$ difference between $21^{\circ} \mathrm{C}$ and $27^{\circ} \mathrm{C}$ ).

Further, a majority of the participants (62.8\%) mentioned that they change their washing machine settings based on weather, amount of clothes, etc. This confirms that if manual controls are provided people use them for energy savings. However, there is a possibility of better knowledge dissemination about energy consumption at different settings, which can further motivate optimized use while accounting for energy consumption.

\section{DESIGN IMPLICATIONS}

The findings we have presented provide a rich basis for rethinking the methods to increase resource conservation among urban Indian residential consumers.

\section{A. Educate Early and Disseminate Widely}

The top motivations for conservation indicate that for urban India, imbibing the conservational habits at an early stage is a simple and effective way to motivate conservation. Schools and parents can teach children at an early stage. For schools, policy-level changes are required like the introduction of environment lessons in all the primary classes. Further, campaigns to make parents understand the importance of teaching sustainability to their children at a young age can help.

When asked about knowledge of different subsidy schemes initiated by the government to motivate energy conservation, only $22.3 \%$ of people knew about any such scheme. It is estimated that $56 \%$ of consumers were eligible for one of the subsidy schemes (i.e., INR 1/unit to those whose monthly consumption is less than 200 units) at the time of the survey, while several other consumers are covered through other subsidy schemes (such as provision of CFL in exchange of regular lights and discounts on energy efficient appliances). While several studies in the past have shown that saving money is the biggest motivator to conserve and providing economic incentives help in improving energy conservation behavior [29], reduced knowledge of such incentive schemes can result in lower than expected impact. Therefore, it is important to disseminate such knowledge to a wide audience.

\section{B. Information-sharing Opportunities}

We found that people are willing to share their personal consumption information without privacy concerns with their relatives, friends and neighbors. Despite this, we found that currently only a small proportion of our participants were aware of their friends' energy bill or their consumption habits. This may be due to the lack of support for such communications. Monthly electricity bills can provide such comparative information at a low cost to all the consumers. While consumption data required for such comparisons already exists with the utility companies, it is only used for personal billing and not for comparative analysis. Recent technological opportunities, such as billing provided by Opower (www.opower.com) exploit the availability of such wide scale information and have been shown to result in significant energy savings [30]. This could also help to establish the presence of environmentally-friendly individuals in the community, which in turn can help motivate not only people who try conserving the most, but also other people in the neighborhood (as mentioned by Froehlich et al. [20]).

Furthermore, future devices can facilitate automatic sharing of such energy conserving information in an individual's social network. For instance, future washing machines could send this message to friends and/or relatives: 'today I washed clothes in cold water, saving energy', or energy meters could broadcast messages about the monthly energy savings.

\section{Convenient Manual Controls}

Comfort and convenience emerged as the major barrier for energy conservation; however a majority of the participants used manual controls for changing their air conditioner and washing machine settings for saving energy instead of more convenient automated options. This could be because of the easy-to-use remote controls for AC. Hence future technologies should provide more easy-to-use manual controls for reducing energy consumption and waste. We further propose that providing an estimate of energy consumption with each setting (e.g., energy consumption at different temperature settings of an Air Conditioner) can further help consumers to make optimal decisions and conserve more.

\section{Price Sensitivity}

Urban Indians are very accepting of the latest technologies, and are among the 'early adopters', yet we found that money is the major motivation for conserving energy. Moreover, similar to Pachauri et al. [17], we found a strong correlation between Indian household energy requirements and their income level. Hence, the best way to provide motivational feedback for energy conservation in the Indian context could probably be in 
monetary terms for the most impact. Also new technological solutions to reduce energy-consumption should be below Rs $5000(\sim \$ 100)$. Due to this price sensitivity, it is important to investigate indirect approaches for monitoring that can result in lower upfront investment and maintenance while still providing useful feedback information. One example of such low cost indirect sensing is Non-Intrusive Appliance Load Monitoring (NILM) whereby data from a smart meter is disaggregated using Machine Learning algorithms [31] to extract appliance level energy consumption rather than monitoring each appliance separately. To the best of our knowledge, so far only one NILM dataset [32] has been publicly released which was collected in the context of developing countries while all others have been performed in the developed countries. Besides cost sensitivity, several other factors such as different appliance ownerships, grid instability and intermittent network connectivity further motivate the need to collect and release many such datasets for advancing NILM research.

\section{E. Appliance-level Information}

Contradictory to previous findings [10], participants wanted appliance level information on their monthly energy bill, and were also willing to invest in technologies that can collect and provide such information. This is crucial in better understanding one's own consumption pattern, and learning from it to perform energy conservation actions. This further motivates the focus on NILM approaches of disaggregating appliance level information at a reduced cost.

\section{F. Robust System Design Accounting for Intermittent Power Supply}

While $24 \times 7$ power supply is taken for granted in many of the developed countries, developing countries like India face frequent power cuts. All participants reported of facing some power cuts regularly. While rural Indians may face multiple hours of power cuts per day, our urban participants reported far fewer cuts. Even so, $35.3 \%$ of our participants reported that on an average they experience more than an hour of power cut daily. In terms of system design, it is therefore important that any monitoring and control system (especially those creating a local in-home mesh across multiple devices) should restore back the same state after power supply recovery as before the power cut. Such a requirement was also reported in [32] who performed extensive home deployment for monitoring in an Indian home.

\section{CONCLUSION}

In this paper, we report on urban Indian motivations to practice deep conservation, barriers to their adoption of conservation practices, views toward sharing consumption related information, and other factors affecting energy conservation. We conducted a large-scale survey $(\mathrm{N}=1724)$ with the urban residential population in the Delhi area of Northern India to gain these insights. While data from such large-scale surveys helps to obtain generalizable results, conducting such surveys is challenging. Even Dourish [33] highlights the problem of scalability in different perspectives. One possibility is to give course work credits to university students for help conducting surveys. Many universities (in India) have Community Work as part of the course requirement, which can be utilized for this purpose. We compared the results obtained from our data with previous work in both the developing and developed world.

We found that urban Indians are motivated to practice conservation, as it is a learned habit and to save money, while comfort and convenience act as major barriers in conservation. These motivations and barriers have been previously reported, however our survey helped us to understand their relative weight. Contrary to previous findings, we did not find tradition, spirituality or moral reasons to be major motivations for conservation. Similarly, we did not find lack of information, money, and safety as major barriers, all of which are discussed in the literature. Interestingly, urban Indians' major motivations were found to be similar to that of people in developed nations, thus hinting that similar eco-feedback technologies might work, while urban Indians barriers were found to be different from people studied in developed world.

Regarding sharing energy data, our participants have minimal privacy concerns in sharing the data with their relatives, friends and neighbors, but were hesitant about making the data public or sharing it on their social networks. We found that residential consumers in developing nations are not only interested in energy monitoring devices, but also appliance level control, and smarter sockets and appliances. This is in contrast with previous findings.

Such similarities and contrast with previous findings suggests that large-scale survey data can not only help in confirming or disproving previous findings, but can also help in obtaining novel generalizable insights.

\section{FUTURE WORK}

Based on the obtained results, we are developing a system to provide appliance-level information to residential consumers and understand their energy use. In the future, we would like to explore other interesting design ideas obtained as insights from this survey, including sharing energy consumption information among peers and designing robust systems for intermittent power supply. In developing regions, power cuts have been described as a government enforced way to reduce energy consumption, though even consumers who practice deep conservation complain about it. Hence studying the phenomenon of power cuts among residential consumers, small-scale business, and large-scale workplaces would be helpful to develop technology to solve the problems associated with it. Research has mostly focused on residential consumers; in the future, it would be interesting to study and gain insights about other stakeholders including utility companies and smallscale businesses, among others. Additionally, apart from people, exploration of infrastructure and policy level changes is a topic for future work. Lastly, studying different countries, different demography, and different stakeholders, can help us to better understand and solve the global challenge of reducing natural resource waste. 


\section{ACKNOWLEDGMENT}

We would like to acknowledge the help of Niharika Sachdeva and Anupam Jain in designing the survey and interactions with the interviewers, and Milan Jain for helping in collecting temperature and power consumption at different $\mathrm{AC}$ settings. Also, we would like to thank all our interviewers who went door-to-door to collect the data, and thanks to participants for their time and patience.

\section{REFERENCES}

[1] "The CIA World Factbook," Central Intelligence Agency, India. [Online]. Available: http://www.webcitation.org/6FJqJCGKV.

[2] "Country Analysis and Briefs," Energy Information and Administration. [Online]. Available: http://www.webcitation.org/6AngIeQWq.

[3] M. Evans, B. Shui, and S. Somasundaram, "Country Report on Building Energy Codes in India,” U.S. Dep. Energy, 2009.

[4] International Energy Agency (IEA), "World Energy Outlook," 2010 .

[5] International Energy Agency (IEA), "Energy Balances of NonOECD Countries," 2007.

[6] S. Can, V. Letschert, M. McNeil, N. Zhou, and J. Sathaye, "Residential and transport energy use in India: Past trend and future outlook," 2009.

[7] M. Alam, J. Sathaye, and D. Barnes, "Urban household energy use in India: Efficiency and policy implications," Energy Policy, vol. 26, no. 11, pp. 885-891, 1998.

[8] "Urban Population," The World Bank. [Online]. Available: http://data.worldbank.org/indicator/SP.URB.TOTL.

[9] M. Chetty, D. Tran, and R. E. Grinter, "Getting to Green: Understanding Resource Consumption in the Home," in Proceedings of the 10th international conference on Ubiquitous computing (UbiComp), 2008, pp. 242-251.

[10] Y. B. Shrinivasan, M. Jain, D. P. Seetharam, A. Choudhary, E. Huang, T. Dillahunt, and J. Mankoff, "Deep Conservation in Urban India and its Implications for the Design of Conservation Technologies," in Proceedings of the SIGCHI Conference on Human Factors in Computing Systems (CHI), 2013, pp. 19691978.

[11] T. Dillahunt, J. Mankoff, E. Paulos, and S. Fussell, "It's Not All About 'Green': Energy Use in Low-Income Communities," in Proceedings of the 11th international conference on Ubiquitous computing (UbiComp), 2009, pp. 255-264.

[12] M. Indraganti, "Thermal comfort in apartments in India: Adaptive use of environmental controls and hindrances," Renew. Energy, vol. 36, no. 4, pp. 1182-1189, Apr. 2011.

[13] D. Vyas, "Domestic Artefacts: Sustainability in the context of Indian Middle Class," in Proceedings of the 4th international conference on Intercultural collaboration (ICIC), 2012, pp. 119-128.

[14] J. Pierce, D. J. Schiano, and E. Paulos, "Home, Habits, and Energy: Examining Domestic Interactions and Energy Consumption," in Proceedings of the SIGCHI Conference on
Human Factors in Computing Systems (CHI), 2010, pp. 19851994.

[15] A. Woodruff, J. Hasbrouck, and S. Augustin, "A Bright Green Perspective on Sustainable Choices," in Proceedings of the SIGCHI Conference on Human Factors in Computing Systems (CHI), 2008, pp. 313-322.

[16] M. Jain, A. Agrawal, S. K. Ghai, K. N. Truong, and D. P. Seetharam, "We are not in the loop': Resource Wastage and Conservation Attitude of Employees in Indian Workplace," in Proceedings of the 2013 ACM international joint conference on Pervasive and ubiquitous computing (UbiComp), 2013, pp. 687696.

[17] S. Pachauri, "An analysis of cross-sectional variations in total household energy requirements in India using micro survey data," Energy Policy, vol. 32, no. 15, pp. 1723-1735, Oct. 2004.

[18] A. Kumar, S. K. Jain, and N. K. Bansal, "Disseminating energyefficient technologies: A case study of compact fluorescent lamps (CFLs) in India," Energy Policy, vol. 31, no. 3, pp. 259272, 2003.

[19] C. Greiffenhagen and S. Reeves, "Is Replication Important for HCI?," in RepliCHI 2013, Proceedings of the CHI2013 Workshop on the Replication of HCI Research, 2013, pp. 1-6.

[20] J. Froehlich, S. Patel, J. A. Landay, L. Findlater, M. Ostergren, S. Ramanathan, J. Peterson, I. Wragg, E. Larson, F. Fu, and M. Bai, "The design and evaluation of prototype eco-feedback displays for fixture-level water usage data," in Proceedings of the SIGCHI Conference on Human Factors in Computing Systems (CHI), 2012, pp. 2367-2376.

[21] "Households by Ownership Status of the Census Houses, Size of the Household and Number of Dwelling Rooms," Census of India, 2011. [Online]. Available: http://www.censusindia.gov.in/2011census/hlo/District_Tables/ HLO_Distt_Table_NCT_of_Delhi.html.

[22] J. Froehlich, L. Findlater, and J. Landay, "The Design of EcoFeedback Technology," in Proceedings of the SIGCHI Conference on Human Factors in Computing Systems (CHI), 2010, pp. 1999-2008.

[23] A. Thieme, R. Comber, J. Miebach, J. Weeden, N. Krämer, S. Lawson, and P. Olivier, "WW've Bin Watching You' Designing for Reflection and Social Persuasion to Promote Sustainable Lifestyles," in Proceedings of the SIGCHI Conference on Human Factors in Computing Systems (CHI), 2012, pp. 2337-2346.

[24] S. Patil, A. Kobsa, A. John, and D. Seligmann, "Comparing Privacy Attitudes of Knowledge Workers in the U.S. and India," in Proceedings of the 3rd international conference on Intercultural collaboration (ICIC), 2010, pp. 141-150.

[25] J. M. Nolan, W. Schultz, R. B. Cialdini, N. J. Goldstein, and V. Griskevicius, "Normative Social Influence is Underdetected," Personal. Soc. Psychol. Bull., vol. 34, no. 7, pp. 913-923, 2008.

[26] J. Pierce, W. Odom, and E. Blevis, "Energy Aware Dwelling: A Critical Survey of Interaction Design for Eco-Visualizations," in Proceedings of the 20th Australian Computer-Human Interaction Conference (OzCHI), 2008, pp. 1-8. 
[27] S. S. Rathi, A. Chunekar, and K. Kadav, "Appliance Ownership in India: Evidence from NSSO Household Expenditure Surveys 2004-05 and 2009-10," Pray. Energy Gr., 2012.

[28] Bureau of Indian Standards, "National Building Code 2005.," 2005.

[29] W. Abrahamse, L. Steg, C. Vlek, and T. Rothengatter, "A review of intervention studies aimed at household energy conservation," J. Environ. Psychol., vol. 25, no. 3, pp. 273-291, Sep. 2005.

[30] "OPower Results," OPower. [Online]. Available: http://opower.com/results.
[31] G. Hart, "Nonintrusive Appliance Load Monitoring," Proc. IEEE, vol. 80, no. 12, pp. 1870-1891, 1992.

[32] N. Batra, M. Gulati, A. Singh, and M. B. Srivastava, "It's Different: Insights into Home Energy Consumption in India," in 5th Workshop on Embedded Systems For Energy-Efficient Buildings (BuildSys), 2013, pp. 1-8.

[33] P. Dourish, "HCI and Environmental Sustainability: The Politics of Design and the Design of Politics," in Proceedings of the 8th ACM Conference on Designing Interactive Systems (DIS), 2010, pp. 1-10. 